\title{
Actualizing Change after Experiencing Significant Mathematics PD: Hearing from Teachers of Color about Their Practice and Mathematical Identities
}

\author{
Richard Kitchen ${ }^{1, *(\mathbb{D})}$, Monica Martinez-Archuleta ${ }^{2}$, Lorenzo Gonzales ${ }^{2}$ and Ali Bicer ${ }^{1}$ (D) \\ 1 School of Teacher Education, University of Wyoming, Laramie, WY 82071, USA; abicer@uwyo.edu \\ 2 Los Alamos National Laboratory Math and Science Academy, Los Alamos, NM 87545, USA; \\ m.archuleta@lanl.gov (M.M.-A.); 1xg@lanl.gov (L.G.) \\ * Correspondence: rkitchen@uwyo.edu; Tel.: +1-307-766-6377
}

Citation: Kitchen, R.; MartinezArchuleta, M.; Gonzales, L.; Bicer, A. Actualizing Change after

Experiencing Significant Mathematics PD: Hearing from Teachers of Color

about Their Practice and

Mathematical Identities. Educ. Sci. 2021, 11, 710. https://doi.org/ 10.3390/educsci11110710

Academic Editors: Andrea Burrows,

Mike Borowczak and

Lieven Verschaffel

Received: 1 October 2021

Accepted: 2 November 2021

Published: 4 November 2021

Publisher's Note: MDPI stays neutral with regard to jurisdictional claims in published maps and institutional affiliations.

Copyright: (c) 2021 by the authors. Licensee MDPI, Basel, Switzerland. This article is an open access article distributed under the terms and conditions of the Creative Commons Attribution (CC BY) license (https:/ / creativecommons.org/licenses/by/ $4.0 /)$.
Abstract: While it is well-documented that students of color and students from low-income communities have often been denied access to a challenging education in mathematics in the United States, less is known about how teachers of color have overcome their deprived educational backgrounds to become teachers of mathematics who implement inquiry-based instructional methods as a means to improve their students' learning and mathematical identities. In this article, we use a sociopolitical theoretical framework to examine how seven elementary school teachers of color characterized their experiences as mathematics students, themselves as teachers of mathematics, and their mathematical identities after experiencing significant professional development in mathematics. All the participants in this study had experienced extensive professional development support in mathematics over a sustained period of time. We demonstrate through the teachers' narratives that, given the deprived mathematics education that the majority of the participants experienced as PK-12 students, having opportunities to participate in significant and focused PD in mathematics over a sustained period transformed how teachers viewed themselves as teachers and positively impacted their mathematical identities.

Keywords: mathematics professional development; teachers of color; mathematical identities

\section{Introduction}

'So I feel like I have gained so much confidence in my own mathematical skills by participating in the Institute because other people recognized that I have something to contribute, that my ideas are worth hearing, and somebody liked it or somebody said, 'Wow, I really liked that model or I liked the way you explained that or I get it because I understand what you're talking about ...' (Gloria, 7th Grade Mathematics Teacher)

'We were spoon-fed when we were in elementary school ... You do this, you line your numbers, you borrowed. We didn't know what we were doing. Now, I am creating thinkers, not spoon-feeding, not telling them what to think or how to think. They are discovering their way of learning mathematics.' (Alana, 3rd Grade Teacher)

While it is well-documented that students of color and students from low-income communities have often been denied access to a challenging education in mathematics in the United States [1-3], less is known about how teachers of color have overcome their deprived educational backgrounds and experiences to become teachers of mathematics who use inquiry-based instruction to improve the learning of their students. Historically, students of color and students from low-income communities generally attend schools with high percentages of novice teachers who are not well prepared to teach mathematics [4,5]. Moreover, students of color and students from low-income communities have 
been largely subjected to instruction as pre-tertiary students that emphasized the memorization of math facts, algorithms, procedures, and mathematical rules [6-8]. To overcome this legacy, teachers of color and teachers who come from low-income communities need significant professional development opportunities [9] to learn the specialized mathematical knowledge needed by teachers [10] and to learn how to use dynamic instructional formats [11,12].

The opening narratives are from teachers who experienced extensive professional development (PD) support in mathematics over a sustained period of time. In this article, we use a sociopolitical theoretical framework to examine how these teachers and five other elementary school teachers of color characterized their experiences as pre-tertiary mathematics students, and how they characterized themselves as teachers of mathematics and their mathematical identities after experiencing extensive professional development in mathematics. The research questions that we address are the following:

1. How do elementary school teachers of color characterize their experiences in mathematics as pre-tertiary students?

2. How do these teachers characterize themselves as teachers of mathematics after experiencing significant mathematics professional development?

3. How do these teachers characterize their mathematical identities after significant PD experiences in mathematics?

Based on the teachers' narratives, we demonstrate that, despite the deprived mathematics education that the participants experienced for the most part as pre-tertiary students, having opportunities to participate in significant and focused PD in mathematics over a sustained period of time transformed how they viewed themselves as teachers and positively impacted their mathematical identities. First, though, we describe the intensive PD support provided to the seven elementary school teachers, all people of color, over many years. We review pertinent research literature that demonstrates the challenges students of color and students who grow up in low-income communities must overcome to become effective teachers of mathematics. We also review the literature on mathematical identity.

\subsection{An Overview of the Institute}

Every academic year since 2009, the Los Alamos National Laboratory Math and Science Academy, (MSA has offered professional development sessions, referred to collectively as the "Institute", for primary and secondary-level teachers of mathematics who teach in culturally and linguistically diverse rural schools in northern New Mexico, USA. ("Culturally and linguistically diverse" (CLD) is used here as synonymous with people who are members of racial minority groups in the United States, also referred to as "people of color.") The Institute includes six full-day sessions and a week of full-day summer sessions. The primary goals of the Institute are to support participating teachers to learn the specialized mathematical knowledge needed by teachers through problem solving, to learn about inquiry-based instruction by experiencing such instruction first-hand, and to experience being members of a community of practice in which respect for the dignity of participants is paramount. In the Institute, teachers consistently solved problems, shared their mathematical solutions in small and whole groups, and had opportunities to examine other teachers' mathematical ideas. The design of the Institute was driven by our collective belief that through experiencing inquiry-based instruction first-hand as learners participating teachers would learn of the benefits of such instruction (e.g., the value of eliciting students' ideas as a means to engage in mathematical discourse and enhance participants mathematical identities) and would want the same for their own students [9]. In addition to the Institute, MSA provides job-embedded professional learning for teachers in their classrooms that includes student-centered coaching, modeling, and lesson observations with debriefings. The continuous contact and collaboration with teachers offer the MSA staff an advanced realization of what teachers need to improve their mathematics instruction. The unofficial motto of the MSA staff is "El trabajo te dice que hacer," which translates as, "The work tells you what to do" to support the needs of teachers of mathematics. In 
this article, we primarily focus on how the Institute affected participants' teaching and mathematical identities, though participants also alluded to how their participation in MSA as a whole impacted them in the interviews conducted.

The vast majority of Institute participants are women and people of color, primarily of Spanish and Native American descent. As pre-tertiary students, most participants attended schools in northern New Mexico where they were largely subjected to years of rote instruction in which they were expected to memorize math facts, algorithms, and mathematical procedures [7]. To counteract their past impoverished experiences in mathematics, participants regularly engaged in solving mathematically-rich, thoughtprovoking problems during the Institute. Teachers also learned first-hand about inquirybased instruction, which included jointly producing mathematical ideas with participants as they engaged in reasoning through mathematical modeling to solve problems [13]. A prominent feature of inquiry-based instruction is the value placed upon mathematical conversations or discourse [14]. Through discourse, students have opportunities to make sense of the linguistic complexity of mathematics by listening to and explaining their ideas to others [15].

Another goal was for Institute participants to have ongoing experiences designed to reform their negative mathematical identities. Research on mathematical identity initially considered issues related to motivation to engage in learning mathematics, but has been expanded to include the study of the relationship between learning and students' sociopolitical contexts [16]. Through noticing teachers' ideas [17] and then publicly leveraging these ideas to extend instruction, a goal of the Institute was to send the indisputable message that teachers have valuable mathematical knowledge that needs to be shared with others (i.e., their community of practice). Being a valued member of a community of practice stands in stark contrast to what participants experienced in mathematics classrooms as pre-tertiary students, classrooms in which they were often made to feel mathematically incompetent and even stupid [9].

\subsection{Students of Color Lack Access to a Quality Mathematics Education}

In the United States, students of color have historically been denied access to a rigorous education in mathematics $[2,8,18]$. Learning expectations tend to be lower for students of color $[19,20]$ compared to those for middle class and upper-middle class White and Asian students $[18,19]$. Mathematics instruction in schools that largely serve low-income, students of color tend to focus on computation over conceptual understanding, facts and rules, and memorization over sense-making [7-9]. Such highly authoritarian, skills-based instruction characterized by low expectations was coined the "pedagogy of poverty" by Haberman [21]. In the United States, it is more likely to find such instruction in schools located in communities of color than in schools located in affluent, White communities. The majority of the participants in this study viewed their schooling experiences negatively. Six of the seven teacher participants grew up in low-income, northern New Mexico communities where they experienced intellectual violence; their cultures and languages were either ignored or minimized [22,23]. For Institute participants, experiencing inquiry-based instruction in which their ideas were central and taken seriously was a major departure from the sort of instruction that they experienced in their youth.

\subsection{Mathematical Identity}

Researchers of mathematical identity have historically considered issues related to student affect such as students' persistence, motivation, and interest in mathematics [24]. Researchers have broadened the notion of mathematical identity to consider relationships among the larger learning environment of the classroom, issues of power, and learning [16,24-26]. Cobb et al. [24] found significant differences between the mathematical identities of students in two classrooms. In a mathematics classroom in which students experienced more traditional mathematics instruction in which learning was largely passive, four of the 11 participants characterized themselves as competent mathematics students. In 
contrast, all 11 students in another classroom where instruction tended to be more dynamic and inquiry-based viewed themselves and their peers as successful. Teachers who worked to support their students to articulate their solutions to tasks were more apt at helping their students develop positive mathematical identities [24]. One of the primary goals of the Institute is to notice and make the ideas of participants, mostly women of color, a central focus of our work [9]. Ultimately, the hope is that, through positioning participants as competent mathematics students, their mathematical identities will be enhanced. Moreover, after experiencing such instruction firsthand, the hope is that participants will want the same for their students; they will return to the classroom, work to improve their instruction, and centralize their students' ideas as important during instruction.

\subsection{Theoretical Framework: Sociopolitical Theoretical Perspective}

In this study, we used a sociopolitical theoretical framework, focusing on educational injustices that limit students' learning opportunities [7]. A sociopolitical lens places the social, cultural, and political context of learning in the forefront when examining phenomena such as whether underserved students have access to a problem-solving based mathematics curriculum and instruction [27], how tracking affects students' access to a rigorous mathematics education [28], and how class and race influence mathematics instruction [8,29]. Using a sociopolitical lens, educational policies and practices are considered from the perspective that differential access to educational opportunities is rooted in differences based on racialized and classed experiences [30]. Using a sociopolitical lens in this study, we take it as a given that the vast majority of teachers who participated in the Institute, most of whom were people of color, had generally experienced mathematics education in impoverished formats given their racial/ethnic backgrounds and the fact that they had grown up in low-income communities [9].

\section{Materials and Methods}

\subsection{Research Context and Participants}

In this study, we used a grounded-theoretical approach [31] to examine narratives collected from interviews conducted with seven teachers who participated. This process involved examining teachers' narratives to understand how the teachers characterized their experiences as mathematics students, themselves as teachers of mathematics, and their mathematical identities. We interpreted teachers' narratives using interpretative methods [31]. The four authors independently coded each of the seven interviews. Each author also used memoing to make sense of codes they developed and to create themes that emerged in their respective analysis of the narratives.

To address our three research questions, we used purposeful sampling. All seven of the teachers who were interviewed as part of this study participated in the Institute over a significant period of time; two years minimum. The seven were invited to participate in the study because of their extensive participation in the Institute. Table 1 provides information about the participants. The seven participants ranged from 38 to 52 years of age. All hold undergraduate degrees in elementary education, and five (Gloria, Suzie, Alana, Camila, and Silvia) had obtained a master's degree in education at the time the study was conducted. All seven are persons of color; three are Native American and four are Hispanic (The term "Hispanic" is commonly used in New Mexico to denote individuals and communities of Spanish descent). In addition, six of the participants are female and one is male. The number of years of teaching experience of the seven participants ranged from 8 to 22 years. 
Table 1. Information about Study Participants.

\begin{tabular}{ccccc}
\hline Pseudonym & Gender Identity & Ethnicity/Race & Role & Years Teaching \\
\hline Gloria & Female & Hispanic & Middle school math teacher & 22 years \\
Suzie & Female & Hispanic & 4th grade teacher & $\begin{array}{c}8 \text { years as teacher, } 7 \text { years } \\
\text { as teaching assistance }\end{array}$ \\
\hline Alana & Female & Native American & 3rd grade teacher & 21 years \\
\hline Camila & Female & Hispanic & 5th grade teacher & 21 years \\
\hline Silvia & Female & Native American & 2nd grade teacher & 15 years \\
\hline James & Male & Native American & 4th grade teacher & 14 years \\
\hline Adriana & Female & Hispanic & 6th grade math teacher & 13 years
\end{tabular}

\subsection{Data Collection}

We conducted semi-structured interviews with the seven participating teachers via Zoom during the Spring 2021 semester. Each interview lasted between 60 and $90 \mathrm{~min}$ and was recorded. The primary purpose of the interviews was to learn how the teachers characterized their experiences as mathematics students, and themselves as teachers of mathematics and their mathematical identities after experiencing significant professional development in mathematics. The interview questions are listed in Appendix A.

\subsection{Data Analysis}

We used a sociopolitical lens to analyze the seven participating teachers' narratives. Specifically, we used interpretive methods [31] to examine the interplay among the teachers' narratives and the social, cultural, and political context of teaching mathematics in northern New Mexico. Each member of the research team independently reviewed each interview and then engaged in a process of open coding of the interviews. Subsequently, the research team met on two occasions via Zoom to engage in an iterative process of coding, reflecting upon, and then clarifying, teachers' narratives [32]. At the conclusion of this process, the research team decided to focus on three research questions because of our collective belief that these questions provided important insights about changes in teachers' mathematical identities after their intensive participation in the Institute.

\subsection{Ethical Considerations}

Ethical approval for this research project was granted through the University of Wyoming's IRB and written consent by each interviewee. To maintain anonymity, pseudonyms are used for participating teachers.

\section{Results}

We organize our findings from the interviews to align with the three research questions as follows: (1) How the teachers characterized their experiences in mathematics as pretertiary students, (2) how teachers characterized themselves as teachers of mathematics after experiencing significant mathematics professional development, and (3) how teachers characterized their mathematical identities after significant PD experiences in mathematics.

\subsection{How the Teachers Characterized Their Experiences in Mathematics as Pre-Tertiary Students}

Participants shared their experiences of their own mathematics learning as pre-tertiary students. In the discussions we had with teachers, they shared significant challenges that they had faced as part of their pre-tertiary education in mathematics. Adriana, who had taught upper elementary students in northern New Mexico her entire career, remembered learning procedural ways of solving mathematics problems and was quite good at following procedures. Such instruction places more emphasis on computation than conceptual 
understanding, memorization of facts, and instruction of rules [7-9]. She explained that she was not necessarily interested in learning why procedures worked:

'When I was in high school, I was taught the procedural way and it worked, and I thought I was good. And I thought I would be great teaching that to other students and it didn't work. In college I was pushed to learn the conceptual way and I resisted it a lot. So I stayed in that same mindset in college, because I didn't have the real life experience to know that the procedural way didn't work for everybody. So I resisted that change. I resisted that idea, that change, that math identity change until I went into the real world. And I noticed then that doing math procedurally didn't work, but that's what I was taught. That's how I could do it.'

Through her experiences in the classroom, Adriana came to realize that if she wanted to help her students learn mathematics, she needed to learn other ways of teaching mathematics. Ultimately, she came to appreciate the need to change her teaching style and her identity as a mathematics learner. Adriana came to believe that she could help more students by having a better grasp of why procedures work, and that, through this understanding, students will be better prepared to be successful in future mathematics coursework.

Three teachers reported that drawing models and using manipulatives in the early grades helped them concretely understand mathematical concepts, but drawings and models were not utilized in the later grades. James, a teacher with experience teaching in public elementary schools, but who was teaching at a Bureau of Indian Education (BIE) elementary school when this interview took place, explained, " $\mathrm{I}$ ' $\mathrm{m}$ one who has to draw a model. I have to, I have to go there first. I have to make sense of the problem, and draw some kind of model. From a model I can move into an equation and then an explanation." James continued by sharing that he struggled to understand subtraction and that models were not provided for him to help him understand subtraction. He described how the procedure was emphasized over understanding:

'One thing that I remember as an elementary student was when it came to subtraction, I never understood. I don't know if it was just the way it was explained to me, just that procedural process. Like when it came to subtracting zeros, the whole regrouping, I did not understand that process at all.'

James tried to tell his teachers that he did not understand what the process of "borrowing" was and why it worked, but felt ignored and was pushed to move on. He was told, "Just do it. That's how it's done." He came to realize that the teacher probably did not understand regrouping himself or did not know another strategy for subtraction. This was a common experience among the participants; teachers most likely did not understand underlying concepts themselves and so they taught mathematics in a procedural manner in which the emphasis was on mimicking the teacher's procedure.

Other teachers in this study shared how being placed in low level mathematics classes hurt their mathematical identities. Gloria, who had taught a range of grade-levels in New Mexican elementary and middle schools, struggled to see herself as a mathematics learner. She shared her experience of being placed in a remedial mathematics class in junior high school.

'When I got into junior high, I was placed in the lowest math class there was. So right there, I was like, oh, well, I'm really bad. I must really be bad at math if I got placed here. So, I guess that my math identity began. I thought I'm not good enough. I'm not smart enough. I don't get it, and so I was afraid. When I entered college, I knew I wasn't going to take high level math classes and tried to avoid anything that had to do with math.'

Silvia, a teacher who had taught both 2nd and 4th grade at a BIE Pueblo elementary school in northern New Mexico, shared her experience of being placed into a "math lab" (remedial) class in middle school. Despite loving mathematics in the early elementary 
grades, Silvia had difficulty with fractions and decimals and was placed into the math lab, a remedial class in middle school.

'When I tested into the general math class, one of my classes ended up being a math lab. So it was kind of like the extra help that I needed. So I had two math classes. One was the regular math class and then a math lab. I would go to the math lab and I was getting worksheets. There'd be instructions on what to do. A lot of it was like percents, decimals and fractions. It was kind of a way for me to catch up, but I had to kind of catch up on my own because there wasn't real direct instruction. It was more like worksheets and going at your own pace.'

Silvia's experience in the math lab was much like what many students of color have historically experienced in U.S. schools; traditional instruction focused on memorization and procedures $[7,8]$. Moreover, Silvia's mother did not know how to advocate for her to have access to a more challenging mathematics curriculum when she was in school: "I didn't really understand all of that at that moment. I didn't really understand. My mom didn't understand the kind of level of math that I should be at." While Silvia spent 7th grade year in the general mathematics class, other students were taking pre-algebra. Fortunately, Silvia had an advocate in her 7th grade math teacher; the teacher recommended she be placed in algebra in 8th grade. Silvia shared the experience of being placed in algebra without having a strong foundation in pre-algebra:

'In eighth grade, teachers were seeing that I was understanding. So, they bumped me into algebra. I went into Algebra I because that's where they said I should be, but I didn't have the pre-algebra foundation that I should have gotten in 7th grade. I was always trying to catch up. I still always struggle with fractions and percents and decimals, because I never really had instruction (in these areas).'

After graduating from high school, Silvia wanted to pursue a degree in environmental science. As an undergraduate at one of the most prestigious universities in the United States, Silvia quickly learned that she was unprepared for the rigors of college mathematics. Given her experiences in middle and high school, Silvia knew that she was not well prepared and was discouraged from continuing the science degree she sought. She shared,

'I just didn't feel prepared. Even though I had taken calculus in high school, I just didn't feel prepared. So that was kind of discouraging. And for me, that was a feeling of, I did not belong at my school, because I was not smart enough to get through those classes. So, I dropped the classes.'

These negative mathematics experiences changed her college path. Silvia began taking classes in social justice and focused on comparative studies in race and ethnicity. She was later advised to consider the education program since she had shown a passion for the future of her community.

Camila, a teacher who had taught upper elementary grades in New Mexico public schools for her entire career, shared that mathematics made sense to her in elementary school since she was allowed to use models, charts and drawings. However, that all changed in middle school as students were expected to learn mathematics using only procedures. Since she could memorize steps and procedures, mathematics classes were easy for her. Nevertheless, Camila came to realize that she did not have a strong understanding of mathematics. In middle school, Camila could solve problems by following procedures that she had been taught, but rarely understood why the procedures worked:

'So I get into middle school and it was the same thing (solving problems using procedures we had been taught). Why do I have to do this? And it was always because that's just what you do it. I could follow procedures left and right. I could solve anything. I could memorize procedures. But a lot of times I just wouldn't do my work because I thought, why am I going to have to do 50 problems using the same procedure when I already know how to do it? And I don't really understand why I'm doing it. That cycle continued through high school ... I 
remember really depending on my dad to help me make connections from what I was doing in school and how they would be applied in the real world.'

The experiences teachers shared in their early learning of mathematics were quite similar. They rarely shared experiences in which they felt successful in learning mathematics in the early grades. In addition, their experiences in secondary mathematics illustrate that they were generally not supported to experience mathematical success. Many of the teachers' narratives demonstrate that their teachers rarely helped them make sense of why the mathematical procedures and algorithms they were taught worked. Their understanding of mathematical concepts was fragile and limited their capacities to succeed in future mathematics courses.

\subsection{How Teachers Characterized Themselves as Teachers of Mathematics after Experiencing Significant Mathematics Professional Development}

Teachers expressed how their participation in the Institute, which some had participated in it for over 10 years, had positively impacted their understanding of the mathematics they taught. Silvia credited her 11-year connection to the Institute with being able to "see" fractions as a division operation. She recalled her surprise at being able to clearly understand an oral explanation that provided insight about how 24/8 is equivalent to 24 divided by 8 and how this insight contrasts with simply applying the traditional algorithm of $24 \div 8$ to derive the solution of 3 . Silvia also described insights derived from examining how $25 / 8=24 / 8+1 / 8=31 / 8$ as compared to simply applying the traditional algorithm of $25 \div 8=3 \mathrm{R} 1$. She explained:

'He wasn't writing it out, he wasn't showing it. He was just verbally saying it, and I could totally follow and understood everything that he was saying. And so, then I thought about it later and (asked myself) could I, a few years ago, have followed and understood that conversation? I guess it's obvious that you've grown in your understanding of math.'

Six of the seven teachers expressed less confidence in their abilities to teach mathematics two grade levels above the highest level they had previously taught. In addition, sixth-grade mathematics and algebra, the "gatekeeper" to other STEM fields and college success [33], presented a challenge for most of the teachers. For example, Silvia revealed, "But sixth grade, like watching what Freddy (the sixth-grade teacher) does and seeing the level of sixth-grade math, I just feel like, I don't know that I could do that." James was anxious about algebraic equations, but was comfortable teaching fourth grade: "I could teach it (fourth grade) in my sleep. I would like to build a deeper understanding of mathematics going back to algebra and algebra II ... I think there's a way for me to really see algebra in a different way than I've never seen before, where it's more conceptual rather than abstract." Gloria felt confident in her abilities to teach seventh-grade mathematics, the grade she was teaching. However, she echoed James' anxiety about algebra:

'As far as my math teaching, I think what has helped me is my confidence in my math skills and my understanding has improved so that I can help students that have difficulty. I'm not yet confident in teaching algebra, if I went above where I'm at right now, I think it would be a little scary for me, like high school math.'

As part of their experiences in the Institute, teachers experienced inquiry-based instruction that was designed to pique their curiosity as they solved challenging problems and were asked to explain and justify their mathematical thinking [34,35]. Alana, a BIE teacher at a northern New Mexico Pueblo elementary school, had incorporated the Institute's inquiry-based model in her teaching style. "So, I think that was one of my biggest takeaways from the Institute, choosing student work, having them present, and even the progression of how to present so that all the kids can understand using different models." The progression that Alana is referring to are the five practices that Smith and Stein [36] identify that teachers can use to help orchestrate productive mathematical discussions, practices that were modeled for the teachers during the Institute. Alana also had her 
students "section their notebooks into three sections. They have to show me a model. They have to come up with an equation that connects to the model and the problem. They label their equation and explain the model they use and how they got to their answer." In Figure 1, an example is given that demonstrates how students in Alana's class created models, equations, and explained how to solve the following task:

Ms. Yost has a rope that is 28 feet long? She would like to cut the rope into 4 equal pieces. What is the length of each piece of rope? Use models, numbers, and words to communicate your mathematical thinking.

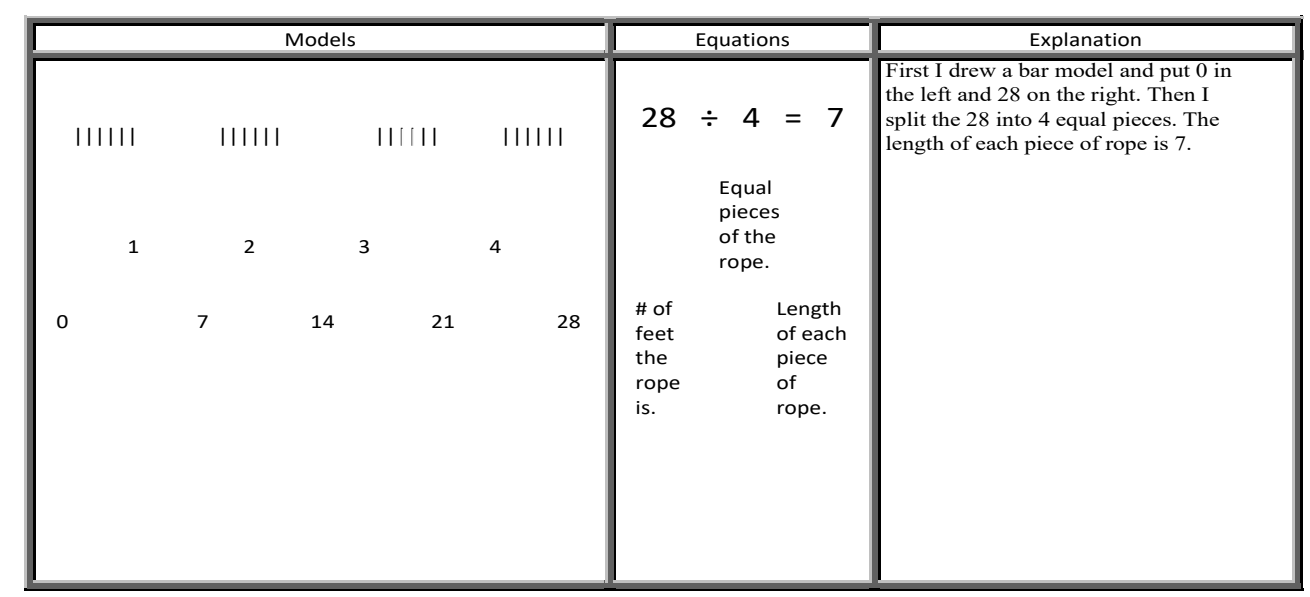

Figure 1. Alana's students provide models, equations and explanations to solve a task.

One of the essential features of the Institute that teachers reflected on was how they regularly shared their mathematical ideas with their peers during sessions. Many teachers were not initially comfortable sharing their ideas during the first Institute sessions they attended; they worried that they could make mistakes or that their level of mathematical understanding would be judged negatively by others. After a couple of sessions, though, teachers felt safe and shared their ideas more freely with others. One of the most commonly shared experiences that teachers transferred from the Institute to their instruction involved learning how to support students to generate their own mathematical ideas, share their ideas with others, and compare and contrast these ideas. For example, Gloria said, "Um, having that time to, to view other people's work, to have them explain it, to ask questions, to make those connections. And being able to explain my own thinking has built up my confidence in my own math skills."

Teachers also discussed how working in an environment in which it was okay to make mistakes was another feature of the Institute that improved their motivation to want to learn new mathematical ideas. Moreover, teachers shared how working in a safe and collaborative environment during the Institute validated their own thinking and helped them build their confidence in their abilities to do mathematics. Suzie, a 4 th grade teacher who also had significant experience as a teaching assistant, shared:

'You feel that you can do math, you know, you feel like you're validated in your thinking and your confidence, even if it's in one little aspect of mathematics, you've owned it. I don't say did it correctly because it's not about doing something correctly. It's about an idea, a strategy that can lead to an answer, and it may not necessarily be the right answer in the end, but your strategy got you to that point. And your way of thinking got to that point. So yeah, the confidence that you get from that math identity, whenever you, you feel like you did it ... So, that creates that confidence.'

Suzie added that "when the Institute instructor allows us to speak up about our strategies, our procedures, and the way we're thinking, we become stronger math educators. We tend to see our misconceptions and correct them in a safe environment." Suzie also shared how her experiences as a learner in the Institute had impacted her instruction: 
"asking students to explain their mathematical thinking has been a real big shift in my experience. It's also helped me be able to grasp those concepts a little stronger as I'm teaching them." Teachers must have strong conceptual mathematical understandings to be able to teach mathematics for understanding [10,37].

Gloria's take-aways from the Institute concerned the importance of collaborative discussions and mathematical modeling that she had integrated into her teaching style. Her biggest takeaway was her burgeoning questioning techniques that promote students in deriving mathematical insights and learning on their own. Gloria explained: "Show me, show me, you know, show me what you're thinking, draw it out, draw a model. This is something I've completely learned through the Institute." We have found that after teachers participate in the Institute for an extended period of time, many have begun to mimic the instructor's teaching moves in their classrooms and to develop their style of inquiry-based lesson delivery.

When Adriana first attended the Institute, she was "really stuck on the procedural, throwing those numbers out there, getting it done. That's what I was taught." The Institute pushed Adriana to think differently, "I think that's what made me a successful teacher, understanding that students needed to know the why behind the math and understand the concepts, rather than just knowing a procedure and memorizing a procedure." Adriana, like the other teachers, came to the understanding that to help students become mathematical thinkers, they needed to become mathematical thinkers themselves:

'I've really brought kids out of their shell and had them think about mathematics in a way that they hadn't thought about it before. I got them communicating with each other, sharing ideas, writing down their mathematical thoughts when they really couldn't even express them in the beginning of our mathematics class. And just opening those conversations about why does the math work, what is the concept behind the procedure? I think I really opened up their mind to a world of mathematics that they hadn't really been exposed to before. I think that's what really made me successful is understanding that students really needed to know the why behind the math and understand the concepts rather than just knowing a procedure and memorizing a procedure.'

In addition to working to help their students understand mathematics, teachers wanted their students to experience mathematics in ways that they never had as pretertiary students. Specifically, as demonstrated in Adriana's narrative, teachers wanted students to learn how to communicate their mathematical ideas and to ultimately come to see themselves as capable mathematics students.

\subsection{How Teachers Characterized Their Mathematical Identities after Significant PD Experiences}

During the interviews, teachers made an explicit connection between their students having conceptual mathematical understanding and developing positive mathematical identities. They made this connection through reflecting on their experiences as learners in the Institute. For instance, the teachers described how their confidence in their abilities to do mathematics increased during the Institute by studying patterns and relationships found in mathematics rather than through memorizing unconnected facts and procedures. Adriana shared how focusing on developing her students' conceptual understanding helped her students achieve better results on standardized tests while also positively impacting their mathematical identities:

'I think that's what led to their, um, huge gains on the standardized assessments because they could write a paragraph about how they completed a mathematical problem. And it wasn't the steps. It wasn't the procedures, it was the concepts. So, yeah, I saw a lot of students change throughout time and I'm seeing it even now that I'm teaching fifth grade. I've only had these students for four weeks ... their mathematical identities have changed significantly already.' 
Teachers provided specific information about how to develop the conceptual understanding of their students based on what they had learned during the Institute. They noted how during the Institute they were regularly asked to solve problems through applying mathematical modeling such as drawings, manipulation, and a variety of representations. For example, Adriana shared her growth from teaching for procedural understanding to teaching for conceptual understanding:

'I was exposed to that conceptual math and look at the concept behind the math. Instead of just the procedure, understand what the problem's asking you to find and think about it deeply so that you can come to an understanding and figure it out instead of just looking for the clues. I was able to change the mathematics program there at the middle school to something that was more conceptual based. Um, so that was kind of a win for me because I had been doing a lot of work with them to kind of see that conceptual side of the mathematics. And there are a lot of great strategies that we've talked about over all the different professional developments that we had together.'

The teachers had the opportunity to develop positive mindsets about mathematics through their participation in the Institute over an extended period of time. As discussed previously, they incorporated some of the instructional strategies learned during the Institute so that their students could also develop positive mindsets about mathematics and develop positive mathematical identities. The participating teachers demonstrated growth mindsets in mathematics when they stated that they could learn mathematics with the necessary time, guidance, and effort. For example, Suzie shared:

'I've been able to experience for myself in the Institute that, that growth mindset of like, I don't get it yet right now. I don't get it right now, but I will through practice and through discourse and through experiences that I have with colleagues, you know, the way he groups us, the way he has us discuss our math thinking, and then being able to show our math thinking builds that concrete, representational and abstract in my mind. And that's what builds that, that confidence, I think.'

Generating their own ideas and strategies for solving problems in a community of practice while hearing others' ideas and perspectives validated teachers' ideas and led to improved motivation to learn mathematics. Adriana discussed how her experiences participating in the Institute led her to develop a positive mathematical identity and she transferred these experiences into her classroom as outlined in the following:

'I'm not sure that I would have been able to create that mathematical identity that I've created within myself, um, by myself, because I don't know that I would have been able to understand how to do all that stuff or how to teach conceptually, how to learn conceptually. It really was a matter that I learned myself and then I taught it to my students. So if I didn't have that support when I first came out of college ... I don't think I would be as successful as I am ... I really saw their mathematical identity changed significantly from when I got them in fifth grade to when they left in sixth grade ... And I think that's what led to their huge gains on the standardized assessments, because they could write a paragraph about how they completed a mathematical problem. And it wasn't the steps. It wasn't the procedures, it was the concepts.'

The Institute also helped teachers come to understand the importance of productive struggle as a means to positively impact students' mathematics identities. During the Institute, they felt like they were the students, and understood better how students could feel and how they could encourage their students to engage in solving mathematical problems. For example, Suzie talked about how through experiencing productive struggle firsthand, her confidence in mathematics improved: 
'I got to say that that's still not enough because I still get pushed to my limits with my, um, productive struggle. And with my productive struggle, I learned so much more of myself and I become more confident and I can build that mathematical identity for my students through that productive struggle in my own classroom.'

Camila shared how through productive struggle her confidence in teaching mathematics was positively impacted:

'I think some of my strengths are that, you know, I allow my students to struggle. I know that has been difficult for me because it's difficult to see them struggle. And many times I want to jump in and I want to save them right. I want to say, no, no, no, no, no, no, no, no, this is what we have to do. But you know, I have learned that struggle is very important. I also think a strength that when I'm teaching, I don't do all the talking.'

Teachers shared how their connection with MSA staff during and after the Institute led them to be interested in learning new mathematical ideas and held them accountable for continued mathematical learning. For example, Gloria said:

'I really enjoy, um, even still having that connection. So having [MSA staff] come in and, um, share a book or send an email that says, 'Oh, you know, look at this.' Or, you know, like to me, I feel like that still is that accountability. Like it still holds me accountable for I'm continually learning. Like I'm still improving in my math instruction.'

Gloria shared:

'Had I not had the support of MSA and the Institute, I'm not sure that I would have been able to create that mathematical identity that I've created within myself, by myself, because I don't know that I would have been able to understand how to do all that stuff or how to teach conceptually, how to learn conceptually, because it really was a matter of that I learned myself and then I taught it to my students. So if I didn't have that support, when I first came out of college and I've got into the real world and I knew that it didn't work, I don't know. I don't think I would be as successful as I am.'

These narratives point to the sustained support that teachers, particularly teachers of color need from high quality PD in mathematics to overcome the crippling effects of an impoverished pre-tertiary mathematics education. These supports included the Institute and, as reflected in their narratives, job-embedded professional learning provided by MSA staff in participating teachers' classrooms.

\section{Discussion}

In this study, we examined how seven elementary school teachers of color characterized their experiences as mathematics students, and how they characterized themselves as teachers of mathematics and their mathematical identities after experiencing significant professional development. Considering the first research question about how the teachers of color characterized their experiences in mathematics as pre-tertiary students, the teachers shared challenges that they faced as mathematics students. For instance, some expressed how in their early schooling experiences they had mathematical questions that were often ignored by their teachers. Teachers conjectured that most likely their teachers lacked conceptual understanding themselves, so they taught mathematics in a procedural manner similar to how they had been taught. Teachers also shared how their mathematical identities had been negatively affected through being placed in low level mathematics classes. Adriana was an outlier in this regard; she was a high-achieving mathematics student and wanted to teach mathematics at the middle school level. Although some participants reported having some positive early elementary mathematics learning experiences, things changed as they moved into later grades. Specifically, participants reflected on how 
they were taught mathematics with little conceptual understanding. Moreover, because of their inadequate preparation in mathematics, teachers' capacities to pursue more advanced mathematics coursework and careers involving mathematics were limited.

With respect to the second research questions, we learned that significant and sustained participation in the Institute had positively impacted teachers' mathematical knowledge, helped them learn how to incorporate inquiry-based instruction in their classrooms, and influenced teachers to want to offer similar instruction to benefit their students. The example provided by Silvia exemplifies how teachers' mathematical knowledge had become more flexible through their experience in the Institute. Moreover, through their experiences in the Institute, they learned about the importance of understanding why particular algorithms and procedures worked. In addition, they learned that through sharing their mathematical thinking with one another, they were able to further develop their mathematical thinking while learning how to justify it. Teachers also discussed the value of using purposeful questions [38] with their students to press students to continually develop their explanations. Lastly, after experiencing mathematics in new and exciting ways, participating Institute teachers wanted their students to experience mathematics similarly. While differences existed among the teachers based on their abilities and willingness to incorporate inquiry-based instruction in their classrooms, the teachers' narratives provide tangible examples of how their instruction had changed for the better based upon their participation in the Institute.

Regarding the third research question, teachers noted how their mathematical identities had been positively affected because of specific features of the Institute. In particular, they noted the importance placed in the Institute on teacher ownership of mathematical ideas or perspectives and how these ideas were compared and contrasted to further enhance teachers' mathematical knowledge. Teachers pointed to the value of creating a safe learning environment for their students in which students could make mistakes without fear of reprisals. Based on their experiences in the Institute, the teachers' believed that their students could be successful in mathematics with the necessary guidance and support, just as they had experienced success in the Institute. Through their experiences in the Institute, teachers developed positive mathematical identities and were continually changing their instruction so that their students could develop more confidence in their mathematical abilities and an interest in mathematics. Lastly, the teachers gave credit to MSA staff who validated their professionalism while holding them accountable for their continuous learning through the classroom-level supports that MSA provided teachers.

From a sociopolitical perspective, the teachers lack of access to a challenging education in mathematics was not coincidental, but reflects the teachers' racialized and classed experiences as pre-tertiary students [30]. The teachers grew up in communities of color and attended schools where their teachers were not generally prepared to teach mathematics for understanding, given that many of them had experienced impoverished mathematics instruction themselves as PK-12 students [9]. Schools located in low-income urban and rural communities of color face similar challenges as northern New Mexican schools. These schools often employ elevated percentages of novice teachers who are generally not well prepared to teach mathematics [4,5]. Moreover, teachers at schools located in low-income, communities of color often lack the skills and expertise needed to engage their students in a rigorous education in mathematics [2,8,9]. Through providing teachers of color ongoing access to inquiry-based instruction and problem solving in which their ideas were frontand-center, the Institute gave the teachers opportunities to learn first-hand the benefits of such instruction as a means to combat historical injustices that they had experienced as pre-tertiary students so that they could be empowered to do the same for their students.

We argue that the sort of rigorous and sustained mathematics PD that is offered through the Institute and the MSA in general needs to be a national priority, particularly at this historic moment of reckoning in the United States with the nation's racist past and structural racism that has normalized educational injustices. Teachers who teach in schools situated in low-income communities of color have unique professional needs. They need 
access to deep and sustained mathematics PD to overcome the historic legacy of racism in the United States, which has resulted in low-income students of color being denied access to a challenging education in mathematics. Even teachers such as Silvia who had graduated from a prestigious U.S. university have benefitted from attending the Institute over many years; Silvia's pre-service teacher education program was not sufficient to prepare her to learn the specialized mathematical knowledge needed by teachers [10], nor did it prepare her to use dynamic instructional formats [13] such as inquiry-based pedagogy. In summary, high quality mathematics PD needs to be targeted for schools located in communities where high percentages of teachers experienced an impoverished education in mathematics as a means to overcome the historic legacy of racism in the United States.

A limitation of this study is that only seven teachers who had participated in the Institute participated in the study. There were teachers who participated in the Institute who were not as profoundly influenced by their participation in the Institute as these seven teachers. It is important to highlight, though, that these seven teachers had all participated in the Institute for a significant period of time and all had classroom-level supports provided by MSA for four years or more. This points to an important implication of this study: To have a significant impact on the specialized mathematical knowledge of teachers of color who have experienced an impoverished mathematics education, teachers must have consistent and ongoing access to professional development in mathematics. In our view and based upon the teachers' narratives, this PD should have a dual focus on developing teachers' mathematical knowledge, specifically the knowledge they need for the grade level they teach, and providing teachers with opportunities to experience inquirybased instruction first-hand. The teachers also pointed to the importance of being part of a community of practice in which they could get help when needed. As teachers' specialized mathematical knowledge [10] is developed in a supportive community, they experience mathematical success and the joy of doing mathematics with their peers. Subsequently, the teachers' mathematical identities are also enhanced [9]. Another limitation of this study is that our findings are based solely on teachers' narratives, and we were not able to triangulate our findings with classroom observations. Thus, we were not able to corroborate teachers' declarations about how the PD had affected their practices, their mathematical identities, and their students' identities.

The Institute intentionally targeted breaking the cycle of poorly prepared teachers teaching mathematics in an impoverished manner by simultaneously focusing on improving teachers' specialized mathematics knowledge and having the teachers experience inquiry-based instruction directly in a community as a means to inspire them to see the benefits of employing such instruction for their students [9]. As teachers develop more positive mathematical identities, they want the same for their students. Consequently, by intentionally offering teachers long-term access to high quality mathematics PD, the generation of students that the teachers teach will have opportunities to learn challenging mathematical content and develop positive mathematical identities themselves thus breaking an historical cycle.

Author Contributions: Conceptualization, R.K., M.M.-A. and L.G.; methodology, R.K. and M.M.-A.; validation, M.M.-A., L.G. and A.B., formal analysis, R.K., M.M.-A., L.G. and A.B.; investigation, R.K., M.M.-A., L.G. and A.B.; data curation, R.K., M.M.-A., L.G. and A.B.; writing-original draft preparation, R.K.; writing-review and editing, R.K., M.M.-A., L.G. and A.B. All authors have read and agreed to the published version of the manuscript.

Funding: This research received no external funding.

Institutional Review Board Statement: The study was conducted according to the guidelines of the Declaration of Helsinki, and approved by the Institutional Review Board of the University of Wyoming (protocol code \#20210202RK02939, date of approval 2 February 2021).

Informed Consent Statement: Informed consent was obtained from all subjects involved in the study.

Data Availability Statement: Not applicable. 
Conflicts of Interest: The authors declare no conflict of interest.

\section{Appendix A. Individual Teacher Interview Protocol}

(1) How many years have you been teaching?

(2) What grade level are you currently teaching?

(3) What grade levels have you taught and where have you taught?

(4) When you think back about your successes as a math teacher, what are those successes? PROBE: Based on the teacher's response, ask questions to elicit specific information related to a success or successes that the teacher names.

(5) How would you generally characterize your experiences in math in grades K-12? Can you share a story with us about something that happened to you as a math student that really impacted you in a big way? PROBE: Based on the teacher's answer, ask specific probe questions such as: "You said that your experiences in math were good in the elementary grades, but not so great in high school. What made your math experiences in the elementary grades better than your math experiences in high school?" OR "You just shared that not so happy story with us about what happened to you in Algebra class in high school. How has that impacted the way you approach teaching your students math?" etc.

(6) Can you tell us about the math content courses that you took in your teacher education program? How many courses did you take and did these courses help prepare you to be an effective teacher of mathematics?

(7) How would you characterize yourself as a math teacher? What are your greatest strengths as a math teacher and what areas of your math teaching would you'd like to improve in? PROBE: Could specifically ask about the teacher's beliefs about math teaching. For example, ask: "What teaching strategies do you use to help students learn math?"

(8) How comfortable are you understanding the math concepts typically taught at your grade level? How about math concepts typically taught a grade level or two above the grade you teach?

(9) What are some reasons you might hesitate to implement something new in math? For example, you have participated in the Institute for the past _ years. In those sessions, you have learned about inquiry-based instruction that involves actively engaging students in math lessons. Have you tried to implement ideas related to inquiry-based instruction with your students? Why or why not? PROBE: What are some challenges you have faced associated with implementing inquiry-based instruction in your math classes? What have you done to help you feel prepared to implement inquiry-based instruction? What sort of supports do you need to use inquiry-based instruction in your math classes?

(10) In the Institute, one of the goals has been to demonstrate the value of including participants' mathematical ideas in instruction. As you may recall, participants are regularly called on to share and explain their solutions to problems in both small group and whole group. A reason to do this is to help participants realize that they have wonderful math ideas that need to be shared with their peers. Hopefully, this leads to participants developing positive mathematical identities. Can you talk about your mathematical identity and how your participation in the Institute has impacted your mathematics identity? PROBE: What challenges have you found may be associated with you having a positive mathematical identity? What sort of supports do you need to have a positive identity as a math teacher?

(11) How important is it to you that your students develop a positive mathematics identity? What are some practical strategies that you use to help your students develop a positive mathematics identity?

(12) We've discussed challenges that you've faced to change your instruction to be more inquiry-based. If we haven't already discussed it, can you talk about your interest in potentially changing your instruction in these ways? What supports exist in your 
district or school to try and change your instruction in these ways? POTENTIAL PROBES: How important is it to you to change your instruction in these ways? How might you and/or your students benefit from making these instructional changes?

(13) We've discussed challenges that you've faced to have a more positive mathematical identity. Is there anything that you'd like to add to this conversation that we haven't already discussed?

(14) Is there anything that you'd like to add to our conversation about your experiences in the Institute and potential challenges/barriers you've faced to change your math instruction?

\section{References}

1. Aguirre, J.; Herbel-Eisenmann, B.; Celedón-Pattichis, S.; Civil, M.; Wilkerson, T.; Stephan, M.; Pape, S.; Clements, D.H. Equity Within Mathematics Education Research as a Political Act: Moving From Choice to Intentional Collective Professional Responsibility. J. Res. Math. Educ. 2017, 48, 124-147. [CrossRef]

2. Kitchen, R.S.; DePree, J.; Celedón-Pattichis, S.; Brinkerhoff, J. Mathematics Education at Highly Effective Schools that Serve the Poor: Strategies for Change; Lawrence Erlbaum Associates: Mahwah, NJ, USA, 2007.

3. Leonard, J.; Martin, D.B. Beyond the Numbers and Toward New Discourse: The Brilliance of Black Children in Mathematics; Information Age Publishing: Charlotte, NC, USA, 2013.

4. Ingersoll, R.M. Teacher Turnover and Teacher Shortages: An Organizational Analysis. Am. Educ. Res. J. 2001, 38, $499-534$. [CrossRef]

5. Ingersoll, R.M.; May, H. The Magnitude, Destinations, and Determinants of Mathematics and Science Teacher Turnover. Educ. Eval. Policy Anal. 2012, 34, 435-464. [CrossRef]

6. Davis, J.; Martin, D.B. Racism, assessment, and instructional practices: Implications for mathematics teachers of African American students. J. Urban Math. Educ. 2008, 1, 10-34. [CrossRef]

7. Kitchen, R.S. Getting real about mathematics education reform in high poverty communities. Learn. Math. 2003, 23, 16-22.

8. Martin, D.B. Race, Racial Projects, and Mathematics Education. J. Res. Math. Educ. 2013, 44, 316-333. [CrossRef]

9. Kitchen, R. The power of their ideas: Leveraging teachers' mathematical ideas in professional development. Intern. J. Math. Educ. Sci. Technol. 2020. [CrossRef]

10. Hill, H.C.; Rowan, B.; Ball, D.L. Effects of Teachers' Mathematical Knowledge for Teaching on Student Achievement. Am. Educ. Res. J. 2005, 42, 371-406. [CrossRef]

11. Loucks-Horsley, S.; Stiles, K.E.; Mundry, S.; Love, N.; Hewson, P.W. Designing Professional Development for Teachers of Science and Mathematics, 3rd ed.; Corwin Press: Thousand Oaks, CA, USA, 2010.

12. Sztajn, P.; Hackenberg, A.J.; White, D.Y.; Allexsaht-Snider, M. Mathematics professional development for elementary teachers: Building trust within a school-based mathematics education community. Teach. Teach. Educ. 2007, 23, 970-984. [CrossRef]

13. Staples, M. Supporting Whole-class Collaborative Inquiry in a Secondary Mathematics Classroom. Cogn. Instr. 2007, 25, 161-217. [CrossRef]

14. Herbel-Eisenmann, B.A.; Cirillo, M. Promoting Purposeful Discourse: Teacher Research in Mathematics Classrooms; National Council of Teachers of Mathematics: Reston, VA, USA, 2009.

15. Kooloos, C.; Oolbekkink-Marchand, H.; Kaenders, R.; Heckman, G. Orchestrating Mathematical Classroom Discourse About Various Solution Methods: Case Study of a Teacher's Development. J. Math.-Didaktik 2020, 41, 357-389. [CrossRef]

16. Gibbons, Y.M.; Martin, D.B. Mathematics Success and Failure among African-American Youth: The Roles of Sociohistorical Context, Community Forces, School Influence, and Individual Agency. Contemp. Sociol. A J. Rev. 2001, 30, 407. [CrossRef]

17. Jacobs, V.R.; Lamb, L.L.C.; Philipp, R.A. Professional Noticing of Children's Mathematical Thinking. J. Res. Math. Educ. 2010, 41, 169-202. [CrossRef]

18. Flores, A. The opportunity gap. In Promoting High Participation and Success in Mathematics by Hispanic Students: Examining Opportunities and Probing Promising Practices; National Education Association: Washington, DC, USA, 2008; Volume 1, pp. 1-18.

19. Diversity in Mathematics Education (DiME) Center for Learning and Teaching. Culture, race, power and mathematics edu-cation. In Second Handbook of Research on Mathematics Teaching and Learning; Information Age Publishing: Charlotte, NC, USA, 2007; pp. 405-433.

20. Milner, I.H.R. Analyzing Poverty, Learning, and Teaching Through a Critical Race Theory Lens. Rev. Res. Educ. 2013, 37, 1-53. [CrossRef]

21. Haberman, M. The Pedagogy of Poverty versus Good Teaching. Phi Delta Kappan 2010, 92, 81-87. [CrossRef]

22. Joseph, N.M.; Smith, A. Black woman first, mathematician second: Toward an understanding of Black women's constructions of mathematics identity. Presented at the 2018 American Educational Research Association Annual Meeting, New York, NY, USA, 13-17 April 2018.

23. Mondragón, J.B.; Stapleton, E.S. Public Education in New Mexico; University of New Mexico Press: Albuquerque, NM, USA, 2005.

24. Cobb, P.; Gresalfi, M.; Hodge, L.L. An Interpretive Scheme for Analyzing the Identities That Students Develop in Mathematics Classrooms. J. Res. Math. Educ. 2009, 40, 40-68. [CrossRef] 
25. Boaler, J. The development of disciplinary relationships: Knowledge, practice, and identity in mathematics classrooms. Learn. Math. 2002, 22, 42-47.

26. Cobb, P.; Hodge, L.L. Culture, Identity, and Equity in the Mathematics Classroom. In A Journey in Mathematics Education Research; Springer: New York, NY, USA, 2010; pp. 179-195.

27. Kitchen, R.S. Privilege in mathematics education: Some reflections on Whiteness. In Interrogating Whiteness and Relinquishing Power: White Faculty's Commitment to Racial Consciousness in STEM Classrooms; Peter Lang Publishing: New York, NY, USA, 2016; pp. 57-71.

28. Boaler, J. Changing students' lives through the de-tracking of urban mathematics classrooms. J. Urban Math. Educ. 2011, 4, 7-14. [CrossRef]

29. Gutiérrez, R. A “gap gazing" fetish in mathematics education? Problematizing research on the achievement gap. J. Res. Math. Educ. 2008, 39, 357-364. [CrossRef]

30. Battey, D. Access to mathematics: A possessive investment in whiteness. Curric. Inq. 2013, 43, 332-359. [CrossRef]

31. Creswell, J.W.; Poth, C.N. Qualitative Inquiry and Research Design: Choosing Among Five Approaches, 4th ed.; Sage Publications: Thousand Oaks, CA, USA, 2018.

32. Miles, M.B.; Huberman, A.M.; Saldaña, J. Qualitative Data Analysis: A Methods Sourcebook; Sage Publications: Thousand Oaks, CA, USA, 2013.

33. Edwards, T.G. Some Big Ideas of Algebra in the Middle Grades. Math. Teach. Middle Sch. 2000, 6, 26-31. [CrossRef]

34. Marshall, J.C.; Horton, R.M. The Relationship of Teacher-Facilitated, Inquiry-Based Instruction to Student Higher-Order Thinking. Sch. Sci. Math. 2011, 111, 93-101. [CrossRef]

35. Warshauer, H.K. Productive struggle in middle school mathematics classrooms. J. Math. Teach. Educ. 2015, 18, 375-400. [CrossRef]

36. Smith, M.S.; Stein, M.K. Five Practices for Orchestrating Productive Mathematics Discussions; National Council of Teachers of Mathematics: Reston, VA, USA, 2011.

37. Ma, L. Knowing and Teaching Elementary Mathematics: Teachers' Understanding of Fundamental Mathematics in China and the United States; Lawrence Erlbaum Associates: Mahwah, NJ, USA, 1999.

38. National Council of Teachers of Mathematics. Principles to Actions: Ensuring Mathematical Success for All; National Council of Teachers of Mathematics: Reston, VA, USA, 2014. 